\title{
Prácticas territoriales y de resistencia contemporáneas de los pueblos Chuschagasta y Tolombón (Valle de Choromoro, Argentina)
}

\section{Macarena Del Pilar Manzanelli ${ }^{1}$}

${ }^{1}$ Departamento de Derecho y Ciencia Política-Universidad Nacional de La Matanza. CONICET. Buenos Aires, Argentina

https://orcid.org/oooo-0002-7414-0431

Correo electrónico: mmanzanelli@unlam.edu.ar
Recibido

septiembre de 2019

Aceptado

julio de 2020

doi: $10.34096 /$ cas.i52.7469

Palabras clave

En este artículo propongo analizar las prácticas de resistencia de dos colectivos que han sido subalternizados, las comunidades-pueblo Los Chuschagasta y Tolombón, para legitimar su forma de vida colectiva ante un contexto de conflictos territoriales. Específicamente, indago en cómo han resignificado las labores de siembra, de cría del ganado y su cultura material a partir del oficio cerámico. Dichas prácticas territoriales han sido históricamente deslegitimadas por sectores dominantes -familias terratenientes y el sistema estatal- debido a que se caracterizan por una organización comunitaria-colectiva del espacio y de las relaciones sociales-culturales, ambas basadas en su cosmovisión originaria-diaguita. Las reflexiones trabajadas en este artículo son producto del trabajo de investigación etnográfico iniciado en el año 2015 con estas dos comunidades-pueblo diaguitas del valle de Choromoro (actual provincia de Tucumán, Argentina), quienes sufren constantes avasallamientos y hostigamientos de sus derechos indígenas.

\section{Contemporary territorial and resistance practices of the Chuscha- gasta and Tolombón Peoples (Choromoro Valley, Argentina)}

\footnotetext{
Abstract

This article analyzes the resistance practices of subalternized groups, the Chuschagasta and Tolombón communities-people, which aim at legitimizing their collective life form in the context of territorial conflicts. Specifically, I look into how these groups have reframed practices of sowing, cattle raising and their material culture through ceramic craft. These territorial practices have been historically delegitimized by dominant sectors -land-owning families and the state system- because they are characterized by a community-collective organization of space and of social-cultural relations, both based on their native-diaguita worldview. The ideas developed in this article are the result of ethnographic research that started in 2015 among these two indigenous diaguita communities-Peoples from the Choromoro Valley (current province of Tucumán,
}

Prácticas territoriales: Resistencias; Pueblo diaguita; Multiculturalismo neoliberal; Conflictos territoriales

\section{Key words}

Territorial practices; Resistance; Diaguita people; Neoliberal multiculturalism; Territorial conflicts 
Argentina), who are the object of constant hostility and overriding of their indigenous rights.

\section{Práticas territoriais e de resistência contemporânea dos Pueblos Chuschagasta e Tolombón (Vale de Choromoro, Argentina)}

\section{Resumo}

Palavras-chave

Práticas territoriais; Resistências; Povo diaguita: Multiculturalismo neoliberal; Conflitos territoriais
1. Terratenientes es una categoría usada por los chuschagastas $y$ los tolombones. El formato itálica lo empleo para referir y destacar sus expresiones y categorías.
Este artigo propõe analisar as práticas de resistência para legitimar a própria forma de vida coletiva em um contexto de conflitos territoriais de dois grupos que foram subalternizados: as Comunidades-Pueblo Chuschagasta e Tolombón. Especificamente, indago no modo em como tem se renovado os trabalhos de semeada, da criação do gado e a sua cultura material através do ofício cerâmico. Ditas práticas territoriais foram historicamente deslegitimadas pelos setores dominantes - famílias terratenentes e o sistema do Estado - porque que baseiam-se em uma organização comunitária de organização coletiva do espaço e das relações sociais e culturais, sustentadas por uma cosmo-visão de origem cultural diaguita. As reflexões trabalhadas neste artigo são produto de uma pesquisa etnográfica iniciada no ano de 2015 com estas comunidadesPueblos indígenas diaguitas do Vale do Choromoro (na atual província de Tucumán, Argentina). Seus habitantes sofrem avassalamentos e fustigações constantes no que respeita aos seus direitos como indígenas.

\section{Introducción}

"Lo único que queremos es vivir en paz, tranquilos en nuestro territorio, en nuestra casa. No le hacemos daño a nadie, nuestra vida es esto, cuidar las cabras, vacas, animales que tenemos, atender la siembra y la casa" (Registro de campo, comunidadespueblo Los Chuschagasta y Tolombón, Tucumán, enero-agosto 2018) ha sido una de las frases que se repiten una y otra vez a lo largo de las comunidades-pueblo Tolombón y Chuschagasta ante los hostigamientos y deslegitimaciones que sufren a diario por parte de las familias terratenientes ${ }^{1}$ de la zona en complicidad con el Estado. Encuentro a esta expresión iluminadora para indagar en el proceso de resignificación, revalorización y legitimación de prácticas territoriales diarias tales como los modos de siembra, de cría del ganado y del oficio cerámico. En este sentido, la hipótesis que persigue el artículo es que dichas prácticas constituyen resistencias, dado que reivindican una forma de vida colectiva, y permiten entender otra relación con el territorio, con sus significados, lógicas y códigos de vida identitarias y culturales. La concepción del espacio, así, deja de ser una mera cosa, un soporte material, y adquiere la noción de espacio vivido y sentido de acuerdo con su cosmovisión originaria (Barabas, 2004; Benedetti, 2011).

En los siguientes apartados comienzo por señalar quiénes son las comunidades-pueblo Chuschagasta y Tolombón, detallo en la distribución del espacio y en aspectos materiales y sociales de su vida diaria, de forma tal contextualizar las tensiones por los usos del territorio entre las familias comuneras y las terratenientes, de los cuales derivan los conflictos territoriales. Luego, refiero a la forma en que llevé adelante el trabajo de investigación. En segundo lugar, explico los condicionantes de comunalización y territorialización implícitos en el marco de derecho multicultural neoliberal. A continuación, 
desarrollo cómo los chuschagastas y los tolombones han revitalizado y resignificado sus prácticas territoriales en pos de resistir a los continuos hostigamientos y deslegitimaciones. Finalmente, ofrezco reflexiones en torno a lo trabajado.

\section{Las comunidades Los Chuschagasta y Tolombón y los conflictos por el uso del territorio}

Las comunidades indígenas Los Chuschagasta y Tolombón pertenecen al PuebloNación Diaguita y se encuentran ubicadas en el segundo distrito del departamento de Trancas, valle de Choromoro, dentro de la microrregión Cuenca Tapias-Trancas. Se encuentran a 22 kilómetros de distancia una de la otra sobre la ruta provincial $\mathrm{N}^{\circ} 312$.

En el caso de Los Chuschagasta, sus puntos límites son hacia el noreste la Ruta Nacional $\mathrm{N}^{\circ}$ 9, atravesada por el río Vipos, que continúa hasta llegar a la bifurcación dirección oeste que empalma con la Ruta Provincial 312 (km 52 a km 12), paralela al río Chuscha y al río Choromoro. Hacia el sur se encuentra el Río Ñorco y luego la localidad de Ancajuli y hacia oeste, la comunidad indígena Potrero Rodeo-Grande y la comunidad indígena Tolombón

Los Chuschagasta se encuentra organizada en cuatro bases territoriales: Chuscha, La Higuera, El Chorro y Ñorco. Desde el año 2002, los chuschagastas cuentan con el reconocimiento estatal a partir de su inscripción en el Registro Nacional de Comunidades Indígenas (en adelante, RE.NA.CI), $\mathrm{N}^{\circ} 4811$, con personería jurídica $\mathrm{N}^{\circ} 03 / 2002$ y cuentan con el relevamiento técnico, jurídico y catastral con Resolución INAI ${ }^{\circ}$ $450 / 2014$ conforme a la ley nacional 26.160 .

La comunidad indígena Tolombón limita hacia el este con la Comunidad Indígena de La Angostura; al sur, con la Comunidad Indígena de Potrero Grande y la Comunidad Indígena de Chasquivil; al norte, con la Comunidad Indígena Indio Colalao; y al oeste, con la Comunidad Indígena Amaicha del Valle. Desde el lado sur, se accede por la Ruta Provincial $\mathrm{N}^{\circ} 312$; por el lado norte, desde la ciudad San Pedro de Colalao, por la Ruta Provincial No 311 (Arenas y Ataliva, 2017). Desde el año 2001, los tolombones cuentan con el reconocimiento estatal a partir de su inscripción en el RE.NA.CI como Comunidad Indígena Pueblo Tolombón, con personería jurídica $\mathrm{N}^{\circ}$ 053/2001 y relevamiento territorial $\mathrm{N}^{\circ} 576$. Se organiza en diez bases, seis territoriales: Potrero, Gonzalo, Rearte, Tacanas Grandes, Tacanas Chicas y Hualinchay; y cuatro bases de apoyo, tres en Tucumán (Los Nogales, El Cadillal y Tafí Viejo) y una en el sur del conurbano bonaerense (Temperley, provincia de Buenos Aires). Pertenece desde el año 2011 a la organización política territorial indígena ENOTPO (Encuentro Nacional de Organizaciones Territoriales de Pueblos Originarios).

$\mathrm{Al}$ recorrer ambas comunidades-pueblo pude apreciar dos tipos de áreas: las parcelas y las de campo abierto. Me interesa hacer énfasis en estas últimas para entender los usos dados al territorio y los conflictos que suscitan. Algunas de las bases de ambas comunidades, como Chuscha y La Higuera, en Chuschagasta, y Potrero y Tacanas Chicas, en Tolombón, cuentan con terrenos individuales - parcelas- y con títulos de propiedad individual. Dichos títulos fueron obtenidos luego de un "loteo" realizado por la provincia de Tucumán hace aproximadamente cinco décadas. Estas bases se caracterizan por tener mayor densidad poblacional (aproximadamente 130 familias, es decir, más de la mitad de la población total de Los Chuschagasta, y alrededor de 150 familias, es decir, tres cuartos de la población total de Tolombón), con una disposición urbanizada, es decir, con un trazado regular y lineal de las viviendas con acceso a distintos almacenes, clubes, escuelas, radio y capillas ubicados a lo largo de las rutas provinciales $\mathrm{N}^{\circ} 312$ y 311. A su vez, no presentan suficiente espacio para cultivar y poder criar animales, 
especialmente aquellos de porte mediano y grande -como caballos, vacas y cabras-, los cuales pastan cerro adentro en el monte. En cambio, en las zonas de campo abierto, como en El Chorro y Norco (Chuschagasta) y en Gonzalo y Rearte (Tolombón), las familias comuneras cuentan con extenso espacio para aprovisionarse de lo necesario para el día a día. Entre las actividades cotidianas se destacan las tareas vinculadas a la cría y cuidado de animales como yeguarizos, chanchos, ovejas, cabras y vacas, de las cuales también se obtiene leche para realizar los quesos y quesillos. Otras labores son el cultivo y la siembra. Los cercos son mayoritariamente compartidos entre las familias, en las "mesadas" - planicies utilizadas como cerco de siembra comunitario compartido por las familias comuneras- donde siembran diversas variedades de plantas, como maíz criollo, arveja, zapallo, avena y alfalfa para los animales, por ejemplo. También entre los cultivos frecuentes se encuentran el cayote y plantas frutales como duraznos, manzanas, higos, ciruelas y, de forma acotada, la quinua, a partir de los cuales elaboran dulces y conservas.

Otras prácticas que reflejan cómo es la vida diaria en las bases de campo abierto es la recolección de leña: "sacamos la leña, sacamos lo que es para los techos [...]. Todo comunitario. Pastoreo de acá a allá, están los animales de uno y del otro" (Registro de campo, comunidades-pueblo Los Chuschagasta y Tolombón, Tucumán, febrero 2018) tal como me indicaron en diversas oportunidades al conversar sobre sus formas de vida. Asimismo, los chuschagastas y los tolombones realizan trabajos artesanales sobre cuero, sobre cerámica y con tejidos.

Como se puede apreciar, especialmente en las áreas de campo abierto, los usos colectivos del territorio conforman el sustento para la vida de los chuschagastas y los tolombones. A su vez, representan el epicentro de los conflictos con las familias terratenientes: tanto en El Chorro y en Ñorco (Chuschagasta) como en las denominadas "mesadas" de Gonzalo y Rearte (Tolombón). En este sentido, la diferencia de tenencia de la tierra entre las bases, es decir, entre las que poseen títulos privados -figura político-jurídica sobre la que se creó el Estado argentino y provincial en desmedro de las colectivas- y las que cuentan con el relevamiento técnico, jurídico y catastral realizado por el INAI -que, sin embargo, no es respetado-, impacta en las garantías de seguridad que se tiene sobre ellas. En este sentido, los conflictos territoriales reflejan la superposición de estas formas de tenencia sustentadas en diferentes relaciones sociales de acuerdo con factores económicos, políticos, proyectos estatales e intereses de grupos de poder (Arenas, 2003), tal como ocurre con las familias terratenientes.

En el caso de la comunidad-pueblo Los Chuschagasta, los y las comuneras mencionan que, hacia mediados del siglo $\mathrm{XX}$, los primeros miembros de la familia terrateniente Amín se instalaron en Chuscha y La Higuera y comenzaron a arrendar para sacar leña y así "quemar ladrillos", actividad a la que comenzaron a dedicarse. También recuerdan que, a partir de entonces, comenzaron a decir que eran los dueños de las tierras. Una vez que los primeros Amín fallecieron, sus hijos se dividieron el territorio; situación que generó el aumento de los hostigamientos para los chuschagastas, por ejemplo, al colocar un portón que les prohibía el paso para ir a buscar leña con el argumento de que "ellos eran los dueños". El 12 de octubre del año 2009 se produjo el mayor momento de tensión y gravedad cuando el terrateniente Darío Luis Amín, junto con dos expolicías Luis Humberto Gómez y José Eduardo Valdivieso Sassi, asesinaron a la autoridad tradicional Javier Chocobar e hirieron a otros tres comuneros referentes y autoridades, Andrés Mamaní, Emilio Mamaní y Delfín Cata. El motivo de este nefasto episodio fue la constante intención de la familia terrateniente Amín de ocupar las tierras de los chuschagastas con el fin de explotar comercialmente su territorio, particularmente la cantera de lajas, lugar donde ocurrió el asesinato. 
Por su parte, la comunidad-pueblo Tolombón también cuenta con numerosas e históricas situaciones de hostigamientos, amenazas y hechos violentos, los cuales fueron judicializados a partir de la década de 1990 y comienzos de 2000. Muchas de las causas se mantienen activas hasta el día de la fecha. Se destacan, en la base de Gonzalo, el conflicto del comunero don Santos Ríos, quien fue demandado por la familia terrateniente Guerinao -familiares de los terratenientes Critto- por la "mesada" ubicada en una de las lomas de Gonzalo. Luego, hacia el año 2016, otro golpe difícil de sortear para los tolombones fue la pérdida de los cercos comunitarios de la familia Cayata junto con la quema del denominado quincho comunitario en la base de Gonzalo a manos de los terratenientes Critto. Este acto de desidia reflejó la búsqueda constante por parte de las familias terratenientes de vulnerabilizar la integración comunal debido a que el quincho comunitario no se trataba solo de una estructura o un inmueble, sino que poseía una relevancia simbólica central para la integración comunal, pues era un lugar de encuentro que no era propiedad privada-individual de ningún comunero-comunera.

Otra de las disputas territoriales notorias ha ocurrido en la base de Rearte Sur. Hacia el año 2007, el delegado Domingo Mamaní junto al secretario general Carlos Villagra y a los comuneros Mario Miguel y Celin Córdoba, entre otros, fueron denunciados por hacer uso de la llamada mesada de abajo, de aproximadamente 9 hectáreas. Por último, destaco que, en junio del año 2017, la Corte Suprema de la Justicia de Tucumán falló en contra del comunero Donato Nievas en la base de Rearte. Esta sentencia habilitó a que las familias terratenientes -de apellidos López de Zavalía, Critto, Torino y Salemereiteraran sus amenazas, hostigamientos y activaran nuevamente causas, tanto contra el comunero Donato Nievas como contra el resto de la comunidad.

En esta investigación extraigo ideas del trabajo de campo realizado durante los viajes al territorio desde el año 2015 (diciembre), 2017 (julio-agosto), 2018 (enero-febrero; julio-agosto) hasta 2019 (enero-octubre), basado en la observación participante y en la realización de entrevistas. A partir de estas estadías y de este modo de encarar la pesquisa (Guber, 2011; Balbi, 2012), entablé lazos que me permitieron recorrer el territorio, convivir y compartir actividades con los y las comuneras para indagar sobre sus conflictos y prácticas territoriales y significados asignados.

Asimismo, la investigación fue propuesta en el marco de un trabajo de interculturalidad, basado en el respeto de respetando la visión y tiempos de comunidades-pueblo y en una producción de conocimiento conjunta (Acuto y Flores, 2019). Conforme a ello, realicé la Consulta Libre, Previa e Informada en asambleas comunitarias. La realización de dicha Consulta implica quedar a disposición de si los pueblos permiten o no realizar la investigación. Su importancia radica en reconocer el derecho de autodeterminación que poseen los pueblos originarios en tanto sujetos políticos y de ejercitar críticamente el proceso de interculturalidad, tal como se menciona en el artículo $6^{\circ}$ del Convenio 169 de la Organización Internacional del Trabajo y en la Ley 25.517.

\section{Procesos de territorialización en contexto del multiculturalismo neoliberal: entre las imposiciones estatales y la agentividad indí- gena}

Hacia la década de 1980, con el retorno de la democracia en la Argentina, emerge un marco de derecho considerado multiculturalista neoliberal, que ha buscado reparar el proceso de subalternización hacia los pueblos indígenas iniciado con el orden colonial y continuado en la etapa de conformación del Estado-Nación (Briones, 1998; Hale, 2002; Sieder, 2002; Van Cott, 2002). Las modificaciones en el marco de derecho fueron, en gran parte, impulsadas por distintas organizaciones de pueblos originarios a lo largo 
del país, que han visibilizado sus luchas por el reconocimiento del territorio y de su identidad (Carrasco, 2000; Gordillo y Hircsh, 2010).

Para contextualizar las praxis político-territoriales indígenas presentadas en este artículo, focalizo en las reformas del marco jurídico nacional introducidas por las leyes nacionales 23.302 (año 1985) y 26.160 (año 2006). Por un lado, la Ley 23.302, al crear las unidades étnico-administrativas denominadas Comunidades Indígenas, incorpora una idea etnojurídica de comunalización de forma tal de obtener un estatus jurídico-institucional que habilite el diálogo con el Estado argentino (Briones 1998 y 2005; Carrasco, 2000; Katzer, 2009). Con la instauración de estas unidades, el Estado nacional y los provinciales han regulado una forma de "vida" común -autorizada- para los pueblos originarios, al instarlos a agruparse y organizarse en función de etnias que resalten sus diacríticos/atributos compartidos, tales como el idioma, tradiciones y costumbres, entre otros. Una vez conformadas, debían ser inscriptas en el RE.NA.CI., organismo encargado de asignarles la personería jurídica, de forma tal de obtener un estatus jurídico-institucional que habilite el diálogo con el Estado argentino (Briones 1998 y 2005; Carrasco, 2000; Katzer, 2009). En el caso de Tucumán, la reorganización de la población originaria como comunidades indígenas comenzó entre los años 1997 y 2002 en el Valle Calchaquí.

Por otro lado, la Ley nacional 26.160 declara la emergencia en materia de posesión y propiedad de las tierras y ordena realizar su registro catastral y dominial con la implementación del Programa de Relevamiento Territorial. En el caso de la provincia de Tucumán, donde actualmente se encuentran ubicadas las comunidades indígenas Los Chuschagasta y Tolombón, hacia el año 2009 se llevó adelante dicho proceso en dos etapas: durante los años 2009-2010 y 2011-2013.

Al considerar ambas leyes se entrecruzan las nociones de comunalización y de territorialización: la figura de la "Comunidad Indígena" es interpretada como un requisito de inscripción en el RE.NA.CI. o ante organismos provinciales competentes para la realización del relevamiento territorial. De esta forma, son delimitadas y registradas las tierras y territorios considerados de ocupación "tradicional", "actual" y "pública", es decir, aquellos que responden a los usos territoriales y normas basadas en las costumbres tanto morales como materiales, que permiten probar la posesión y continuidad en el territorio hasta el presente (Arenas, 2013). A partir de lo indicado se pueden apreciar ciertas ambigüedades. Estos dispositivos estatales reconocen, por un lado, la preexistencia de los pueblos originarios a la conformación del Estado argentino y provincial. No obstante, también imponen exigencias y criterios estatales espaciales y simbólicos sostenidos en nociones occidentales de territorialidad. Así, al cartografiar las tierras de los pueblos se establecen límites fijos para ser incluidos en las carpetas jurídicas-catastrales, lo cual produce que otras categorías, como son los territorios inmemoriales, no sean incluidas y reconocidas. A su vez, la regulación estatal ha generado cambios en las formas indígenas de pensar el territorio, al reducir gradualmente las nociones de pueblo y de etnoterritorios en los niveles comunitarios y agrarios (Barabas, 2004, 108-110).

En función de lo dicho, el orden del multiculturalismo neoliberal puede ser comprendido como un marco social-político cultural hegemónico que, a la par que aprueba la diferencia étnica y su preexistencia, limita los poderes de agencia de los sujetos al imponer pautas de organización acompañadas de coordenadas hegemónicas tempoespaciales o de maquinarias estratificadoras y diferenciadoras de inclusión y de exclusión (Alonso, 1994; Grossberg, 2003; Pacheco de Oliveira, 2004; Briones, 2005). En las leyes subyacen definiciones con sentidos esencialistas de la identidad que mediante conceptos como "tierras tradicionales" ocupadas por las comunidades indígenas con personería jurídica, restringen, homogenizan y naturalizan las formas de vida, de movilidad, de 
sociabilidad y de agencia de la población, y construyen así una subjetividad basada en una identidad étnica diferenciadora (Briones, 2016; Trentini, 2016; Espósito 2017).

Asimismo, resulta interesante destacar que en el Programa de Relevamiento Territorial se incorporó la noción de "territorio" que, a diferencia del concepto "tierra", refleja otras formas y lógicas culturales e identitarias de comprender la relación con él y sus usos. En este sentido, la incorporación del término "territorio" adquiere potencialidad si, como señalan la/os investigadores Patricia Arenas y Víctor Ataliva (2017), su abordaje se realiza corriéndose de posicionamientos etnocéntricos. Para nuestro caso de análisis, esta mirada habilita a entender los procesos de territorialización, no solo como las acciones impulsadas por actores dominantes como los estatales, sino también como las prácticas estratégicas que los grupos subalternizados realizan para reapropiarse material y simbólicamente de su territorio (Ataliva, 2008; Maidana, 2011). Esta visión comprende las representaciones que los actores ofrecen al espacio, la noción de espacio vivido, en tanto construcción sociohistórica y de las trayectorias de los actores, sin desatender a las relaciones de poder intrínsecas, de interpelación con las lógicas estatales y de representación indígena (Raffestin, 1993; Lopes de Souza, 2001; Haesbaert, 2004; Maidana, 2011).

En suma, los pueblos originarios se encuentran ante un escenario complejo. En primer lugar, condicionados ante la necesidad de adecuarse a términos como "Comunidad Indígena" y posesión "tradicional", "actual" y "pública" para probar así su continuidad histórica y cultural en el territorio. En segundo lugar, y a pesar de la retórica a favor del respeto a la diversidad cultural respecto de los precedentes marcos políticos de desadscripciones y ocultamiento de la identidad indígena, en la práctica no hay un real reconocimiento a las formas de ocupación del territorio alternas a la histórica y hegemónica visión de la propiedad privada (Briones, 1998 y 2005; Jackson y Warren, 2005; Kraay, 2007; Arocha y Maya, 2008). Estas obstaculizaciones se traducen en la persistencia de situaciones de despojo de sus tierras y territorios, en las que tanto sectores privados como el mismo Estado violan las leyes. En tercer lugar, y en sintonía con lo anterior, actores como las familias terratenientes emplean diversas lógicas y representaciones estigmatizadas con el fin de deslegitimar y apropiarse de los territorios. Una de estas, por ejemplo, es señalarlos como "indios truchos", "oportunistas" y "usurpadores", lo cual banaliza y cosifica el vínculo que mantienen con sus territorios y desconoce, por lo tanto, sus ocupaciones "tradicionales" determinadas por la ley. Otras retóricas empleadas para justificar su intromisión en los territorios indígenas consisten en señalar que las familias comuneras hacen usos poco productivos de la tierra, especialmente en el caso de quienes viven en campo abierto. Dicha calificación de improductividad se vincula con la noción de "atraso" que, históricamente, han recibido los pueblos originarios. Por último, se pueden encontrar acusaciones como "ya no existen indios" o "campos vacíos", negación en la cual subyace el imaginario de una planificación del suelo urbanizada como representación de un lugar habitado, con construcciones contiguas y a la vista, en contraste con la imagen que presenta el monte, donde las casas se ubican de forma irregular -o en red- a lo largo del territorio y no son visibles al no estar a la vera del camino principal.

No obstante estas limitaciones, como se aprecia en lo expuesto, los proyectos hegemónicos, con sus nociones estadocéntricas y racionalidades instrumentalizadoras, no son absolutos ni totalizadores, sino que se encuentran interpelados por los colectivos subalternizados, quienes, aun ubicados en los márgenes del Estado -en tanto sitios territoriales como sociales-simbólicos-, buscan romper con esta racionalidad imaginada (Roseberry, 1994; Ferguson y Gupta, 2002). En este sentido, a lo largo de las décadas, los chuschagastas y los tolombones se vieron expuestos, como una forma de sobrevivencia, a dejar de realizar libremente sus prácticas y costumbres ante el temor a represalias y a la discriminación recibida tanto por las familias terratenientes como 
también por el personal docente en las escuelas; aunque continuaron manteniéndolas de forma oculta dentro de sus hogares. Luego, y ante un contexto contemporáneo de reconocimiento formal de la diversidad étnico-cultural, los chuschagastas y los tolombones han impulsado estrategias de visibilidad, de fortalecimiento político-identitario y de reapropiación territorial, las cuales incluyen la toma de posición como respuesta a la interpelación por parte del Estado y de las familias terratenientes.

Una de las principales consecuencias del recrudecimiento de los conflictos territoriales en los últimos diez años ha sido que los chuschagastas y los tolombones comenzaran a replantearse la categorización estatal-dominante de la Comunidad Indígena al notar la connivencia del Poder Judicial de la provincia de Tucumán con las familias terratenientes. Este replanteamiento conllevó también a resignificar la institucionalidad originaria colectiva, Pueblo, los lazos colectivos indígenas, saberes y la continuidad cultural en el territorio (Manzanelli, 2020), con el fin de poder vivir libre y de forma autodeterminada. Los procesos de autorreconocimiento identitario representan pliegues, puntos de sutura entre las condiciones, reglas y dispositivos dominantes y las formas en que los pueblos indígenas las entienden, las interpretan y se posicionan ante estas (Ramos, 2005; Ramos y Delrio, 2005; García y Valverde, 2007; Ramos, Crespo y Tozzini, 2016). En este sentido, indico el término comunidades-pueblo ya que, por un lado, "comunidades" señala que los chuschagastas y los tolombones se han reorganizado y registrado en el mencionado RE.NA.CI, perteneciente al Instituto Nacional de Asuntos Indígenas (INAI), y obtuvieron la personería jurídica. Por otro, los y las comuneras se autoidentifican bajo la categoría pueblo, y marcan así una distinción entre la forma en que son categorizados desde el Estado nacional y provincial (como Comunidades Indígenas con ocupación "tradicional", "actual" y "pública" demostrada) y sus formas preexistentes organizativas, identitarias y de socialización, con sus conocimientos locales, de memoria oral y de geografía simbólica (Barabas, 2004).

\section{Prácticas y usos colectivos y autodeterminados del territorio}

El proceso de fortalecimiento político e identitario impulsado por los chuschagastas y los tolombones ha consistido en revalorizar distintas prácticas de comunalización y de territorialización, como las vinculadas a la siembra, al cuidado de los animales y a su cultura material a partir del oficio cerámico. Proceso que demuestra, a su vez, formas de reapropiación material y simbólicas del territorio, las cuales incluyen elementos y materialidades representativos para ambas comunidades cargados de sentidos y significados (Ataliva, 2008; Maidana, 2011).

Como se pudo apreciar anteriormente, las labores y usos comunitarios del territorio han sido centrales en la vida de los chuschagastas y los tolombones, y dan cuenta de una forma de espacio vivido y experimentado, más allá del proceso de adecuación ante los dispositivos estatales en tanto reorganización bajo la figura etnopolítica Comunidad Indígena: como lo expresa el siguiente testimonio: "Los trabajos diarios que se hacían antes, nuestros abuelos, siempre eran relacionados a pesar de que antes no estábamos conformados como comunidad, pero sí ellos, hacían, nuestros ancestros hacían, y hay que realizarlos" (Entrevista a Delfín Cata, 29 de enero de 2018, base El Chorro).

Con el fin de llevar adelante este proceso, ambas comunidades-pueblo organizaron asambleas comunitarias con el objetivo de compartir las memorias de los y las comuneras mayores, quienes recordaron y contaron sobre las costumbres de sus antepasados. Para los chuschagastas y los tolombones, ha sido importante revitalizar las técnicas de siembra, aprendidas de generación en generación y que contienen un bagaje experimental, es decir, saberes ancestrales en torno a los tipos de cultivo: "por ejemplo, con el tema de la siembra, que lo he podido charlar allá [refiere a la comunidad de Tolombón] [...] 
lo que hacían nuestros abuelos porque plantaban el maíz y el zapallo juntos" (Ismael Chocobar, entrevista, 29 de enero de 2018). Entre estos conocimientos sobresalen el intercalar distintas semillas de acuerdo con la época del año para poder conservar los nutrientes necesarios para la tierra y recuperar la semilla, es decir, aquellas que provienen de la cosecha anterior, y también los saberes locales sobre los usos de plantas medicinales. A partir del mes de agosto, en el cual se conmemora a la Pachamama y el despertar del ciclo de la siembra -principalmente de octubre a noviembre, con las primeras lluvias-, las familias comuneras comienzan a preparar la tierra: la abonan, la aran y rotan los cercos abonándola, arándola y rotando los cercos de forma tal de dejarla descansar y prepararla para otros ciclos. Este es un tiempo de ofrendarle a la Madre Tierra lo producido durante el año anterior en un acto de reciprocidad y de reconocimiento. Asimismo, dichos intercambios, al basarse en elementos indispensables para la vida diaria muestran que el territorio, simbolizado como Madre Tierra, siempre ha sido considerado como fuente de vida. En concordancia, las palabras de un comunero de la base de Gonzalo -Tolombón- reflejan que lo indispensable para la vida cotidiana proviene de ella:

Vos ponete a pensar uno de dónde vive, vive de la Tierra [...]. Si la tierra nos da los productos para que nosotros comamos. De la tierra sale la papa, sale todo, la hacienda [...] y nosotros consumimos. O sea, lo que la tierra nos da lo que uno come [...]. (Entrevista a Juan Cruz, 28 de julio del año 2018, base Gonzalo)

Estos modos ancestrales de realizar las labores agrícolas también reflejan el vínculo de reciprocidad que mantienen las familias comuneras entre sí. Para arar manualmente el terreno y luego colocar semilla por semilla en los surcos se requiere del trabajo colectivo-comunitario, a partir del cual se vislumbran los intercambios entre los y las comuneras por medio de la reciprocidad de favores. En diversas oportunidades mientras los chuschagastas y los tolombones realizaban actividades agrícolas me indicaron que, en el arar, sembrar y cosechar se mantiene vivo lo comunitario: "no es por plata, sino que él que participa sabe que luego cuando lo necesite será ayudado" (Registro de Campo, comunidades-pueblo Los Chuschagasta y Tolombón, Tucumán, julio 2018) .

Como se puede apreciar, las tareas de siembra permiten vislumbrar que la forma de hacer vida de los chuschagastas y los tolombones, sus prácticas y usos territoriales diarios descansan en ahondar en los saberes y conocimientos transmitidos de generación en generación, tal como lo refleja la noción de memorias-hábito (Rodríguez, San Martín y Nahuelquir, 2016). Los y las comuneras han aprendido de observar a sus padres y abuelos y las han implementado cotidianamente, por lo cual no han sido olvidadas. En otros términos, al mismo tiempo que las prácticas, técnicas y saberes son reproducidos, son resignificados; por lo tanto, recrean lazos afectivos y cognitivos, tanto entre las generaciones actuales como con quienes ya no están. Además, estos modos de realizar las labores agrícolas se encuentran ligados al espacio íntimo, donde justamente las familias comuneras las han conservado por siglos, a pesar de los tratos estigmatizantes recibidos en las escuelas y por parte de las familias terratenientes. Tras estas acciones se encuentran significados sociales y organizativos que se caracterizan por ser colectivos, y que reinterpretan las formas en que los dispositivos estatales, como la ley 26.160, imparten criterios de territorialización y comunalización; por ejemplo, como ocurre con la inclusión del adjetivo "tradicionales" en dicha norma para describir a las formas de ocupación y usos dados al territorio

Junto con el impulso dado para retomar y resignificar el valor de estas técnicas colectivas de la siembra heredadas de sus antepasados mayores, otras de las prácticas territoriales consideradas por los chuschagastas y los tolombones para fortalecer su sentido de pertenencia territorial y colectivo han sido la cría y sacrificio de ganado vacuno, ovino, caprino y porcino, el cual es destinado para su autoconsumo. Los y las comuneras, a 
través de estas, han buscado recrear, por un lado, formas de entender y relacionarse con uno de los componentes del territorio, los animales; y por otro lado también reproducen estos vínculos y lazos comunitarios, de reciprocidad y de complementariedad.

En primer lugar, en diversas oportunidades pude apreciar, tanto en sus relatos como al participar de sus actividades diarias, que la cría y sacrificio del ganado no es igual a la concepción de cría ganadera que poseen otros sectores de la población como pueden ser los productores agropecuarios de la zona y/o las familias terratenientes. En ambas comunidades-pueblo se encuentra una relación particular de vincularse con los animales. Ejemplo de ello es en el momento del carneo, dicha tarea se realiza luego de ciertos pasos que dan cuenta de este vínculo particular, de respeto hacia el animal. Para matar a un animal se lo piala (es decir, se lo enreda de las patas hasta que caiga al suelo), se lo sujeta fuertemente y se lo acompaña en su respiración para calmarlo. Luego se lo deja descansar en un tablón, se lo amarra de las cuatro patas y antes de matarlo se lo mira a los ojos y se le pide perdón, se le da un corte certero en el cuello -degüelle- de modo que no sufra; se deja que su sangre brote, es decir, que llegué a la tierra de donde salió, y se le sueltan las amarras para que pueda seguir su camino con aquellos animales que ya no están.

Como se puede observar, el vínculo y trato hacia el animal refiere a que cada ejemplar es comprendido como un componente del territorio y hace a su equilibrio, por ello, su sangre debe ser devuelta o derramada en él. Así, en las tareas ganaderas subyace la forma comunitaria y colectiva de entender al territorio y a los seres que lo integran, lo cual marca el valor identitario dado por los y las comuneras. En sintonía con ello, en diversos relatos, los chuschagastas y tolombones señalaron que solo se sacrifica al animal para comerlo, al igual que ocurre con la caza: solo se toma lo necesario para la vida y consumo, y se respetan las épocas de cría, momento en que está prohibido matar animales, de forma contraria, se quiebra con el equilibrio natural.

En segundo lugar, ambas comunidades-pueblo utilizan el ganado para el autoconsumo familiar y en sí para toda la comunidad. Durante mis estadías de trabajo de campo, conviviendo con los y las comuneras era frecuente ver cómo se realizan intercambios, donde el valor de uso y de cambio del ciclo de consumo se basa en los lazos de reciprocidad comentados anteriormente con las labores de la siembra: si una familia no tiene carne, por ejemplo, otra le lleva o mismo se intercambian carne por otros alimentos.

Por último, entre las prácticas identitarias-territoriales revitalizadas se encuentra el oficio cerámico. El impulso para retomar el trabajo artesanal sobre cerámica surgió a partir de asambleas comunitarias donde se pensaron los proyectos comunitarios de creación del espacio "Territorio de Memoria, Lucha y Resistencia Javier Chocobar" (año 2015) y el "Encuentro Intercultural de Cerámica en Chuschagasta - Reafirmando la Identidad Diaguita. Inauguración del Taller Comunitario de Cerámica Javier Chocobar" (año 2017).

Los objetivos que se perseguían eran construir algo colectivo y propio, reconectarse con los usos que le han dado sus antepasados a este recurso y bien cultural -la cerámica- y fortalecer la identidad colectiva a través del arte. A partir de estas iniciativas, las familias comuneras comenzaron a hablar sobre la arcilla que se encuentra en el territorio y a recolectarla para los proyectos y actividades. A su vez, se activó un espacio de aprendizaje del oficio cerámico, transmitido a partir del intercambio de saberes por parte de los y las comuneras más grandes. 
La decisión comunitaria de los chuschagastas de elegir el oficio de cerámica se debe a que ha sido el principal material utilizado por sus antepasados para uso ceremonial y para el armado de utensilios en la vida cotidiana:

\begin{abstract}
Cuando nosotros empezamos a pensarlo pensamos que la cerámica es parte de nuestra cultura y tiene que ver con el uso ceremonial, pero también con la vida cotidiana nuestra. [...] Y aparte por lo que sí la cerámica es. Además de ser una pieza tiene una... me sale la palabra temperatura. Es algo cálido. Deja de ser cerámica y hasta pareciera que se integra con el lugar. Es tierra, es territorio. Tiene esa cuestión de vida por más que haya pasado por el horno. Es algo cálido y que no es ajeno a nosotros. Nosotros no queríamos que sea algo de un material ajeno a nosotros. [...] Algo que no tenga que ver culturalmente con nosotros. (Entrevista a Nancy Chocobar, 16 de mayo del año 2016, Buenos Aires)
\end{abstract}

Del testimonio destaco tres aspectos que dan cuenta de la importancia que posee la cerámica para la comunidad en tanto recurso cultural e identitario (Arenas y Ataliva, 2017). El primero de ellos apunta a la frase "la cerámica se integra, es tierra, es territorio", la cual coincide y refuerza la forma en que los chuschagastas se comprenden a sí mismos en relación con el territorio: "somos tierra", "somos parte, de la tierra venimos y a la tierra vamos", "como pueblos originarios tenemos una cosmovisión, un pensamiento, una filosofía de vida de cómo administrar el territorio, como conducirnos, en la vida política propia, cómo conducirnos a nivel salud, a nivel educación. Es una idea holística, integral", (Registro de campo, comunidades-pueblo Los Chuschagasta y Tolombón, Tucumán, julio-agosto 2017 y agosto 2018), tal como reiteraron en diversas ocasiones, por ejemplo, durante los talleres cerámicos, en actividades diarias de recolección de leña y de plantas medicinales, en celebraciones colectivas a la Pachamama, entre otras.

El segundo aspecto relevante consiste en que la cerámica "tiene esa cuestión de vida", como detalló Nancy Chocobar, ya que antes de ser horneada es arcilla, es decir, "es tierra-territorio". Esta asociación entre la arcilla-cerámica y la idea de "vida" aporta otra característica sobre la forma en que ha sido comprendido el territorio: como una entidad con agencia para manifestarse (Allen, 1988; Van Vleet, 2008). En este sentido, a lo largo de mi trabajo de campo escuché numerosos relatos en los que personificaron al territorio-naturaleza indicando que se le debe respeto y que, por lo tanto, se busca vivir en equilibrio con él.

Un tercer aspecto para resaltar es que la cerámica representa un material "propio" de la comunidad, lo cual refuerza su sentido de pertenencia territorial debido a que, como mostré, es el material que han usado sus antepasados-ancestros "desde siempre". A su vez, al dar cuenta de que la cerámica es parte de sus usos del territorio, legitiman su posesión territorial continuada en el tiempo respecto de las múltiples acusaciones por parte de sectores dominantes, entre ellos de la familia terrateniente Amín, como la de ser "indios truchos".

La importancia dada al oficio cerámico a partir de la transmisión de conocimientos también se reflejó en la decisión acerca de cuáles serían los diseños para decorar los utensilios fabricados. Así, por ejemplo, uno de los talleres dictados, el de Figuras en Pequeños Formatos, en el que participé, se inició con la explicación sobre las figuras para moldear en la arcilla como de suris, jaguares, víboras y cóndores bicéfalos, los cuales dan cuenta de una vasta simbología diaguita. La selección de estos diseños se debió, por un lado, a que son los mismos que se encuentran pintados en los restos de vasijas y ollas cerámicas encontrados en el territorio; es decir, son significativas para la comunidad ya que eran empleadas por sus antepasados mayores y ancestros. 
Por otro lado, estas formas zoomorfas representan los cuatro elementos vitales de la naturaleza -el agua (la rena), la tierra (el suri), el fuego (la víbora y jaguares) y el aire (el cóndor)- que explican la vida diaria de los chuschagastas, como en general del pueblo diaguita. Estos cuatro elementos son fundamentales ya que, como señalaron en la comunidad, sin ellos no se puede desarrollar la vida diaria. Por ejemplo, la figura de la rana simboliza el agua. Durante mis estadías de trabajo de campo pude apreciar que para los y las comuneras el canto de la rana anuncia la llegada de las lluvias y, por lo tanto, si habrá épocas de abundante agua o de sequías durante el verano, cuestión fundamental para la planificación de las tareas agrícolas y ganaderas, entre ellas, para saber si es necesario realizar acopio-reserva de comida para el invierno. En otras palabras, los chuschagastas buscaron que en los talleres de cerámica se trabajase con figuras que dieran cuenta de la relación que mantienen con el territorio: en interdependencia con él, como un elemento más y no superior, distinto a la manera en que es considerado en la visión occidental, donde el hombre se halla escindido de la naturaleza y busca controlarla y explotarla con fines productivos-comerciales.

En otras palabras, estas creaciones se encuentran cargadas de simbología diaguita y han sido parte de un proceso complejo de reivindicación identitaria y cultural en el cual el valor de cambio y de uso conlleva un valor identitario (Benedetti, 2012). El oficio cerámico constituye así una forma de arte y un recurso válido para comunicar los conocimientos aprehendidos de generación en generación.

En síntesis, tanto las técnicas ancestrales de las labores de siembra, como la cría de ganado y el oficio cerámico retomados por los chuschagastas y los tolombones encierran un valor que se explica a partir de lo identitario, es decir, de acuerdo con las relaciones sociales-organizativas comunitarias que perduran y dan sentido a la forma de vida de ambas comunidades-pueblo. Este ser y estar en el territorio, que remite a las costumbres de sus antepasados, cobra relevancia en función de los acontecimientos presentes como son los conflictos territoriales, los cuales representan el impedimento para realizar sus formas de vida colectivas territoriales.

\section{A modo de cierre}

En los últimos años, ante el recrudecimiento de los conflictos territoriales y de incumplimiento del Estado provincial de los derechos territoriales indígenas, los chuschagastas y los tolombones han impulsado un proceso de fortalecimiento identitario-político y de reflexión acerca de la forma en que el Estado y las familias terratenientes los ha interpelado. Por un lado, las familias comuneras se han repreguntado por las categorías de comunalización y de territorialización tales como se plasman en las leyes nacionales 23.302 y 26.160. Por otro, sobre las continuas expresiones deslegitimantes que parten de acusarlos de ser "indios truchos" a negar su existencia. Estas instancias de reflexión han incluido tanto los intentos históricos y sistemáticos de asimilación de sus formas de vida que han sufrido desde la época colonial, como también la agentividad de sus antepasados, quienes, a pesar de la invisibilidad hegemónica, han sabido mantener sus costumbres y prácticas identitarias. Actualmente, y en marcos institucionales y políticos de reafirmación de la diversidad étnica-identitaria, aún persisten limitaciones tales como el incumplimiento de las leyes indigenistas y los hostigamientos materiales y simbólicos.

En esta oportunidad, me interesó destacar cómo los chuschagastas y los tolombones se han sabido reponer ante estas acusaciones a partir de la revalorización de sus prácticas y usos cotidianos del territorio, especialmente en las áreas de campo abierto, donde las extensas hectáreas son fundamentales para el sustento diario. Asimismo, estas tierras 
llaman el interés de las familias terratenientes de apropiárselas y controlar sus accesos y uso, funcionales a los avances de las políticas económicas neoliberales.

La revitalización de los modos de siembra, cría y cuidado de animales y el oficio cerámico reafirman, en primer lugar, una organización colectiva del territorio y de las relaciones sociales político-culturales e identitarias in situ. En este sentido, les ha permitido a los chuschagastas y a los tolombones reapropiarse material y simbólicamente de él y de sus conocimientos aprendidos de generación en generación. Una forma de hacer vida basada en el trabajo mancomunado entre las familias comuneras, en los lazos de reciprocidad y en el vínculo con la naturaleza entendido como sustancial. En este sentido, los chuschagastas y los tolombones reivindican que la persona humana y no humana no son entidades escindidas una de la otra, sino que son elementoscomponentes integrados, lo cual, desde una visión instrumentalista y comercial no es compresible ni aceptable como lo es, para ellos, la de los terratenientes.

En segundo lugar, el proceso de reflexión iniciado en torno a sus prácticas territoriales les ha permitido revalorizarlas como recursos culturales-materiales al ser parte del legado ancestral y muestra de la posesión continuada de la comunidad a lo largo del tiempo. A su vez, relegitiman dicha posesión, jerarquizan sus saberes locales, los cuales, lejos de representar "atraso", reflejan, tal como varios comuneros y comuneras me han indicado: "el conocer, y verse reflejado en el territorio. Los terratenientes no conocen el territorio, necesitan que alguien los lleve a mula o caballo porque no conocen y se pierden, no pueden sobrevivir solos aquí en el territorio".

En suma, las prácticas presentadas conforman formas de hacer vida colectiva y de resistencia, al permitir reafirmar los sentidos de pertenencia territoriales, ya que reavivan el sentido colectivo por sobre las individualidades y por sobre el proceso de individuación al que constantemente los empujan estas situaciones conflictivas. Asimismo, son reflejo del trabajo de reapropiación de categorías dominantes tales como usos "tradicionales" del territorio, que permiten reflexionar sobre lo propio, el ser y estar en él, que remiten a sus antepasados mayores y ancestros.

\section{Financiamiento y agradecimientos:}

Este documento es resultado del financiamiento otorgado por el Estado Nacional, por lo tanto queda sujeto al cumplimiento de la Ley № 26.899. Específicamente gracias al financiamiento del Consejo Nacional de Investigaciones Científicas y Tecnológicas (CONICET) y los proyectos de investigación CyTMA2 DER-044 y PROINCE Do44, provenientes del Programa de la Investigación Científica, Transferencia de Tecnología e Innovaciones de la Universidad Nacional de la Matanza y del Programa de Incentivos a Docentes Investigadores de la Secretaría de Políticas Universitarias, respectivamente.

\section{Biografía}

Becaria posdoctoral CONICET-Departamento de Derecho y Ciencia Política-Universidad Nacional de La Matanza. Doctora en Ciencias Sociales y Humanas (UNQ). Mag. en Antropología Social (IDAES-IDES, UNSaM, 2017). Lic. en Ciencia Política (UNLaM, 2013). Docente en UNLaM: Adjunto carrera Lic. en Ciencia Política (UNLaM, 2013 al presente). 


\section{Q Referencias bibliográficas}

》 Acuto, F. y Flores, C. (comps.) (2019). Patrimonio y pueblos originarios. Patrimonio de los pueblos originarios. Buenos Aires: Universidad Nacional de La Matanza, Encuentro Nacional de Organizaciones Territoriales de Pueblos Originarios (ENOTPO), Imago Mundi.

" Allen, C. J. (1988). The Hold life Has: Coca and Cultural Identity in an Andean Community. Washington DC: Smithsonian Institution Press.

»Alonso, A. (1994). The politics of Space, Time and Substance: State Formation, Nationalism and Ethnicity. Annual Review of Anthropology, 23, 379-405.

»Arenas, P. (2003). De campesino a indio: comunidades indígenas en la „puerta de los valles" Tafí del valle, Tucumán, Argentina. Anales Nueva Época, 6, 413-442. Recuperado de http://hdl.handle.net/2077/3246

»Arenas, P. (2013). La participación de Tucumán en el relevamiento territorial de la ley 26.160: una mirada desde las prácticas. Población \& Sociedad, 20(2), 125-136.

»Arenas, P. y Ataliva, V. (2017). Las comunidades indígenas: etnoterritorios, prácticas y saberes ancestrales. Tucumán; Buenos Aires: Ente Provincial Bicentenario.

" Arocha, J. y Maya, A. (2008). Afro-Latin American Peoples. En D. Poole (Ed.). A Companion to Latin American Anthropology (pp. 399-425). Oxford: Blackwell.

"Ataliva, V. (2008). Arqueología, memorias y procesos de marcación social (acerca de las prácticas sociales pos-genocidas en San Miguel de Tucumán). Tucumán: Grupo Interdisciplinario de Arqueología y Antropología de Tucumán, Facultad de Ciencias Naturales e Instituto M. Lilllo, Universidad Nacional de Tucumán.

" Balbi, F. A. (2012). La integración dinámica de las "perspectivas nativas" en la investigación etnográfica. Intersecciones en Antropología, 13(2), 485-499.

"Barabas, A. M. (2004). La territorialidad simbólica y los derechos territoriales indígenas: reflexiones para el estado pluriétnico. Alteridades, 14(27), 105-119. Recuperado de http:// www.redalyc.org/pdf/747/74702706.pdf doi: 10.24275/uam/izt/dcsh/alteridades

" Benedetti, A. (2011). Territorio: concepto integrador de la geografía contemporánea. En P. Souto (coord.), Territorio, Lugar, Paisaje. Prácticas y conceptos básicos en geografía (pp. 11-82) Colección Libros de Cátedra, Buenos Aires: Facultad de Filosofía y Letras, UBA.

"Benedetti, C. (2012). Producción artesanal indígena y comercialización: entre los "buenitos" y los “barateros". Maguaré, 26(1), 229-262.

» Briones, C. (1998). La alteridad del Cuarto Mundo. Una deconstrucción antropológica de la diferencia. Buenos Aires: Ediciones Del Sol.

» Briones, C. (2005). Formaciones de alteridad. Contextos globales, procesos nacionales y provinciales. En C. Briones (Ed.), Cartografías argentinas. Políticas indigenistas y formaciones provinciales de alteridad (pp. 11-44). Buenos Aires: Antropofagia.

» Briones, C. (2016). Caminos de enraizamiento en la mapu: procesos de formación de comunidad en la Norpatagonia argentina. En C. Briones y A. M. Ramos (Eds.), Parentesco y política: topologías indígenas en la Patagonia (pp-53-71). Viedma: Universidad Nacional de Río Negro.

"Carrasco, M. (2000). Los derechos de los pueblos indígenas en Argentina. Buenos Aires: International Work Group for Indigenous Affairs y Vinciguerra. 
"Espósito, G. (2017). La polis colla. Tierras, comunidades y política en la Quebrada de Humahuaca. Buenos Aires: Prometeo.

» Ferguson, J. y Gupta, A. (2002). Spatializing states: toward an ethnography of neoliberal governmentality. American Ethnologist, 29(4), 981 -1002.

" García, A. y Valverde, S. (2007). Políticas estatales y procesos de etnogénesis en el caso de poblaciones mapuche de Villa La Angostura, Neuquén, Argentina. Cuadernos de Antropología Social, 25, 111-132.

》 Gordillo, G. y Hirsch, S. (Eds.) (2010). Movilizaciones indígenas e identidades en disputa. Buenos Aires: La Crujía.

» Grossberg, L. (2003 [1996]). Identidad y estudios culturales: ¿no hay nada más que eso? En S. Hall y P. Du Gay (comps.). Cuestiones de identidad cultural (pp. 148-181). Buenos Aires: Amorrortu.

"Guber, R. (2011). La etnografía. Buenos Aires: Siglo XXI.

" Haesbaert, R. (2004). O mito da desterritorialização: do "fim dos territórios" à multiterritorialidade. Rio de Janeiro: Bertrand Brasil.

» Hale, C. (2002). ¿Puede el multiculturalismo ser una amenaza? Gobernanza, derechos culturales y política de la identidad. En M. L. Lagos y P. Calla (comps.) Antropología del Estado: dominación y prácticas contestatorias en América Latina Guatemala (pp. 286-346). La Paz: Instituto Nacional de Derechos Humanos/Programa de las Naciones Unidas para el Desarrollo.

" Jackson, J. E. y Warren, K. B. (2005). Indigenous Movements in Latin America, 1992-2004: Controversies, Ironies, New Directions. Annual Review of Anthropology, 34, 549-573.

" Katzer, L. (2009). Tierras indígenas, demarcaciones territoriales y gubernamentalización. El caso Huarpe, Pcia, de Mendoza. Avá, 16, 117-136.

» Kraay, H. (2007). Introduction. En H. Kraay (ed.). Negotiating Identities in Modern Latin America (pp. 1-27). Canadá: University of Calgary Press.

"Lopes de Souza, M. (2001). O territorio: sobre espaço e poder. Autonomia e desenvolvimento. En I. de Castro, P. da Costa Gómez y R. Lobato Corrêa (orgs.), Geografia: conceitos e temas (pp. 77-117). Río de Janeiro: Bertrand.

»Maidana, C. A. (2011). Migrantes tobas (qom), procesos de territorialización y construcción de identidades (Tesis doctoral). Universidad Nacional de La Plata, La Plata, Argentina.

»Manzanelli, M. D. P. (2020). “Somos pueblo, con autodeterminación libre y colectiva”: reivindicaciones identitarias-organizativas de los pueblos diaguitas Los Chuschagasta y Tolombón. Tabula Rasa, 34, 111-130. doi:10.25058/2011-2742

»Pacheco de Oliveira, J. (2004). ¿Una etnología de los 'indios misturados'? Situación coIonial, territorialización y flujos culturales. En A. Grimson, G. L. Ribeiro y P. Semán (eds.), La antropología brasileña contemporánea. Contribuciones para un diálogo latinoamericano (pp. 285-322). Buenos Aires: Prometeo.

»Raffestin, C. (1993 [1980]). Por uma geografia do poder. San Pablo: Ática.

»Ramos, A. M. (2005). Trayectorias de Aboriginalidad en las comunidades mapuche del Noroeste de Chubut (1990-2003) (Tesis doctoral). Facultad de Filosofía y Letras, Universidad Nacional de Buenos Aires, Buenos Aires, Argentina.

"Ramos, A. y Delrio, W. (2005). Trayectorias de oposición. Los mapuche y tehuelche frente a la hegemonía en Chubut. En C. Briones (comp.). Cartografías Argentinas. Políticas indigenistas y formaciones provinciales de alteridad (pp-79-118). Buenos Aires: Antropofagia. 
"Ramos, A. M., Crespo, C. y Tozzini, M. A. (2016). En busca de recuerdos ¿perdidos? Mapeando memorias, silencios y poder. En A. M. Ramos, C. Crespo y M. A. Tozzini (comps.). Memorias en lucha Recuerdos y silencios en contextos de subordinación y alteridad (pp. 1350). Viedma: Editorial UNRN. Universidad Nacional de Río Negro

» Rodríguez, M. E., San Martín, C. y Nahuelquier Nahuelquir, F. (2016). Imágenes, silencios y borraduras en los procesos de transmisión de las memorias mapuches y tehuelches. En M. Ramos, C. Crespo y M. A. Tozzini (comps.). Memorias en lucha Recuerdos y silencios en contextos de subordinación y alteridad (pp. 111-141). Viedma: Editorial UNRN. Universidad Nacional de Río Negro

» Roseberry, W. C. (1994). Hegemony and the language of contention. En G. M Joseph y D. Nugent (eds.). Everyday forms of State formation: revolution and the negotiation of rule in modern Mexico (pp. 355-366). NC: Durham, North Carolina: Duke University Press.

» Sieder, R. (2002). Introduction. En R. Sieder (ed.), Multiculturalism in Latin America (pp. 1-24). New York: Institute of Latin American Studies Series, University of London.

»Trentini, F. (2016). Procesos de construcción de la diferencia cultural en el co-manejo del Parque Nacional Nahuel Huapi. Revista de Estudios Sociales, 55, 32-44.

»Van Cott, D. L. (2002). Constitutional Reform in the Andes: Redefining Indigenous-State Relations. En R. Sieder (ed.). Multiculturalism in Latin America (pp. 45-74). New York: Institute of Latin American Studies Series, University of London.

»Van Vleet, K. E. (2008). Performing Kinship. Narrative, Gender, and the Intimacies of Power in the Andes. Austin: University of Texas Press.

\section{Otras Fuentes}

» Ley № 23.302 (1985). Ley sobre Política Indígena y apoyo a las Comunidades Aborígenes. Congreso Nacional argentino, Buenos Aires, Argentina. Recuperado de http://servicios. infoleg.gob.ar/infolegInternet/anexos/200oo-24999/2379o/texact.htm

»Ley $\mathrm{N}^{\circ}$ 26.160. (2006). Declárase la emergencia en materia de posesión y propiedad de las tierras que tradicionalmente ocupan las comunidades indígenas originarias del país, cuya personería jurídica haya sido inscripta en el Registro Nacional de Comunidades Indígenas u organismo provincial competente o aquéllas preexistentes. Ciudad Autónoma de Buenos Aires, Argentina. Recuperado de: http://servicios.infoleg.gob.ar/ infolegInternet/anexos/1200oo-124999/122499/norma.htm 